\title{
Pre-service Teachers Exploring the Role of Pattern-based Reasoning in the Context of Algebraic Thinking
}

\author{
Samuel Obara ${ }^{1 *}$ \\ ${ }^{1}$ Texas State University, San Marcos, Texas, USA
}

Received 19 January 2018 - Revised 23 January 2019 - Accepted 24 January 2019

\begin{abstract}
This paper explores how a group of pre-service elementary school teachers training to become mathematics teachers for elementary schools arrived at generalizations based on patterns. Two representative problems were investigated with these preservice teachers. The focus of this study was how these preservice teachers analyze and symbolize algebraically their generalizations during a problem-solving process. The results indicate that the preservice teachers had difficulty making use of input-output (having two variables in the table) relationships in a generalization process associated with developing symbolic functions. This study identifies the crucial need for introducing students to pattern activities early on in their lives.
\end{abstract}

Keywords: algebraic, generalization, patterns, proof, reasoning, variable

\section{INTRODUCTION}

Patterns play an essential role in algebra, and pattern recognition is an important content area that students at all grade levels should learn - from recognizing simple patterns to analyzing algebraic expressions. Introduction to school algebra is a big change for students from what they have learned. It marks the passing from number-based arithmetic to variables with their symbolic representation. Research indicates that inadequate transition from arithmetic to algebra plays a role in the difficulties students have in algebra (Kaput, 2000; Smith, 2003). There is a need for more discussion about students' thinking processes as they generate rules pertaining to pattern investigations (Smith, 2003). The challenges that arise as a result of students moving from arithmetic-based tasks to algebra-based ones have been studied (Kieran, 1992). The arithmetic that students learn provides the foundation that algebra needs to build on. "Traditionally instructed students who are proficient with numbers need to shift from thinking about finding the answer to thinking about 'finding the right answer' to thinking about the 'numerical relationships' underlying the calculations they perform and the nature of the methods used" (Kilpatrick, Swafford, \& Findell, 2001, p. 271). If elementary school teachers are not equipped with the knowledge to help students make the leap from number and arithmetic to learning about relationships (patterns), then learning functions can be a challenge (McCrory et al., 2012). Helping students see algebra more regarding a relationship (pattern) than just a symbolic manipulation misses the big idea of what algebra is.

\begin{abstract}
Through an emphasis on generalization, justification, and prediction, students can learn to use and appreciate algebraic expressions as general statements. More research is needed on how students develop such awareness. At the same time, more attention needs to be paid to include activities in the curriculum on identifying the structure and justifying. Their absence is an obstacle to developing the "symbol" that constitutes the power of algebra (Kilpatrick et al., 2001, p. 279).
\end{abstract}

Students need to have a sense of patterns to make conjectures, to test conjectures, and to arrive at other generalizations (Cuevas \& Yeatts, 2001). Driscoll (1999) states that "algebraic thinking includes being able to think about functions and how they work and to think about the impact that a system's structure has on calculations" (p. 2). Students often experience difficulty in building algebraic understanding when they are exposed to a particular problem and attempt to generalize a pattern. Many of these difficulties are well established in the research

(C) 2019 by the authors; licensee Modestum Ltd., UK. This article is an open access article distributed under the terms and conditions of the Creative Commons Attribution License (http://creativecommons.org/licenses/by/4.0/). \so16@txstate.edu (*Correspondence) 


\section{Contribution of this paper to the literature}

- The study provides an opportunity to examine deeply the pre-service teachers' thinking on general rules that they may know and how they may or may not utilize those rules in their reasoning.

- The results from the study contribute to the understanding of the benefit of pattern activities that involve verbal and symbolic representation and to the appreciation of the role of algebra as a tool for representing structures of modeling situations.

- Allowing pre-service teachers to construct their patterns, rather than the pattern being constructed for them, gave them the opportunity to discover the patterns themselves.

literature, yet they have to be well integrated into core mathematics curricula for preservice teacher training. Dienes (1961) says that a "generalization which seems to take a long time [for students to develop] is the one from an initial class of small, familiar numbers to 'any number.' If this generalization does not take place, algebra cannot possibly be understood" (p. 289-290). Dienes also points out that students need to comprehend that an algebraic rule is a generalization involving inputs (the domain) to generate outputs (the range).

Smith's study focuses on the connection between the ability to generalize and visualize a relevant pattern for the purpose of developing a set of data points and the capacity for plotting those points or representing the data in various ways. In visualizing how the points seem to be related to the final stage of formulating a function that captures the relationship, "Students' justifications provide a window for viewing the degree to which they see the broad nature of their generalizations and their view of what they deem as a socially accepted justification" (Lannin, 2005, p. 232).

The National Council of Teachers of Mathematics (NCTM, 2000) has been pushing the integration of algebra throughout the school curriculum, beginning at the elementary school level (Chazan, 2008; Kilpatrick \& Izsák, 2008). Algebra as a way of thinking poses a challenge for elementary school teachers (Kaput, 2000; Stephens, 2008) since they went to school in a traditional algebra teaching environment - therefore teaching the way they were taught. The majority of elementary school teachers see algebra as a set of rules and procedures to use in solving problems. This narrow view of algebra creates a barrier to understanding algebra conceptually (Billings, 2008; Stephens, 2008). To think algebraically, one needs to understand the interplay between patterns, functions, and algebra itself. Smith (2003) notes that a focus on those connections lacks in the instructional approach of most elementary school teachers. Additionally, the National Council of Teacher Quality (NCTQ) report notes that elementary school teachers "need to understand algebra as the generalization of the arithmetic they address while studying numbers and operations, as well as algebra's connection to many of the patterns, properties, relationship, rules, and models that will occupy their elementary students" (Greenberg \& Walsh, 2008, p. 55). The report recommended that there be more emphasis on algebra in the preservice curriculum.

The challenge of preparing preservice elementary teachers to meet the vision outlined in the National Council of Teacher Quality report is left up to the mathematics educator. So, the question is, how can the mathematics educator nurture the preservice teachers' algebraic thinking? Smith (2003) observes that the study of patterns and generalization can facilitate algebraic thinking for preservice teachers. There exists extensive research about preservice teachers understanding ideas about numbers, but more needs to be learned in regards to how teachers conceptualize the big idea of algebra (Stephens, 2008). This is exacerbated by a lack of emphasis on helping preservice teachers adopt the vision of algebra advocated by the teacher quality report. Looking at the way preservice teachers generalize patterns and investigating the obstacles and successes faced in the process (Malara \& Navarra, 2003; Warren, 2000) can help in fulfilling the NCTQ vision and also extend the existing research on algebraic reasoning and, more specifically, the generalization of patterns.

The purpose of this study is to investigate the process preservice elementary teachers undergo as they explore the concepts of patterns and generalization as these concepts relate to functions. In doing so, the following research questions were investigated: (a) How do pre-service teachers generalize the numerical patterns they encounter? (b) In what ways do pre-service teachers generalize, sustain or prevent the understanding of generalization? (c) How do preservice teachers' ways of representing data help/hinder in generalizing a pattern?

\section{A FRAMEWORK FOR REPRESENTATIONAL THINKING}

Helping students visualize data and engage in representational thinking is an important step in teaching algebra. A framework for representational thinking, called functional thinking, was created by Smith (2008), based on the work of Kaput (2008). This framework focused on algebra as the study of functions. According to Smith (2008), "Functional thinking ... is representational thinking that focuses on the relationship between two (or more) varying quantities, specifically the kinds of thinking that lead from specific relationships to generalizations of that relationship" (p. 143). Representational thinking involves working with relationships among changing quantities, 
which is the core of algebraic reasoning, which, in turn, is part of the functional reasoning, about which Smith has come up with the following six activities:

Engaging in a Problem Within a Functional Situation

1. Engaging in some physical or conceptual activity.

2. Identifying two or more quantities that vary in the course of this activity and focusing one's attention on the relationship between these two variables.

Creating a Record of Progress

3. Making a record of corresponding values of these quantities, typically tabular, graphical, or iconic.

Seeking Patterns and Mathematical Certainty

4. Identifying patterns in these records.

5. Coordinating the identified patterns with the actions involved in carrying out the activity.

6. Using this coordination to create a representation of the identified pattern in the relationship (Smith, 2008, pp. 143-144).

\section{Patterns}

Patterns can be found everywhere around us. Patterns can be seen in wallpaper, art, fabric and much more. Patterns do not always have to be expressed in the numerical form (National Council of Teachers of Mathematics, 2000), but mathematics has been noted as a subject that studies patterns. As outlined by Zaskis and Liljedahl (2002), there are different types of patterns: number patterns, pictorial/geometric patterns, patterns in computational procedures, linear and quadratic patterns, repeating patterns, and more. For example, in the pattern, 1, 4, 8, 16, a student might see a pattern involving skipping even numbers but be unable to predict the next number. Another student might note that the pattern could be expressed as $1^{2}, 2^{2}, 2^{3}, 2^{4}, \ldots \mathrm{n}^{2}$. This student might, as a result, appreciate the predictive component of algebraic thinking and come up with conjectures about a particular investigation.

\section{Generalization}

Mathematicians and scientists sometimes generate a general law based on patterns. A process of generating a general law (generalization) based on observations and patterns is known as inductive reasoning. Generalization is one of the most important strands of the mathematical thinking process, helping us move from a simple case to conclusions about what is always expected to hold (Driscoll, 1999). The process of observing patterns may lead to making a conjecture, which can only be proved false by a counterexample.

Student activities play a critical role in enabling students to discover patterns and generalize, and "this type of generalization can provide a connection to a referential context that can aid student understanding of symbolic representation, as well as a link to students' prior knowledge of arithmetic" (Lannin, 2005, p. 233). For instance, an activity such as the one in Figure 1 represents oblong numbers - 2, 6, and 12 - as demonstrated by a rectangular shape with dots in each row and column. Based on this problem, teachers can ask students to generate a rule and then use the rule to generate the $100^{\text {th }}$ oblong number.

\section{:::}

Figure 1. Oblong numbers

Providing such activities gives students the opportunity to generate rules to describe patterns they are working to solve. In the process of generalization, students often come up with faulty reasoning by applying operational concepts incorrectly or using guess-and-check inappropriately. Guess-and-check, if not used correctly, can be seen to fit the rule to a given situation. Students would miss the main goal of the problem by not understanding the relationship that exists in a given representation (Healy \& Hoyles, 1999; Mason, 1996; Stacey, 1989).

\section{METHODOLOGY}

It is important for preservice teachers to learn how to meaningfully incorporate problem-solving activities to understand students' thinking as they work on the algebraic problem- solving investigations. Observation of what students say (language) and do is important in determining students' thinking process (Steffe \& Thompson, 2000; Von Glasersfeld, 1995). 
In this study, I have selected a qualitative case study research approach because "qualitative methods permit inquiry into selected issues in great depth with careful attention to detail, context, and nuance" (Patton 2015 p. 257) of learners exploring the role of pattern-based reasoning in an algebraic context. This involves a careful description of the context of the case and in-depth analysis of the topic using multiple sources of evidence so as "to develop an in-depth understanding of a single or explore an issue or problem using the cases as a specific illustration (Creswell, 2018 p. 96). Case study research can be about a case or cases in a real-life context where a selected case can be an individual, a group of individuals, a process, an event, or an activity. A case study is a bounded system in that the researcher states clearly the focus and the extent of the study "with regard to the time period covered by the case study; the relevant social group, organization, or geographic area; the type of evidence to be collected; and the priorities for data collection and analysis" (Yin, 2017 p. 28). In this study, a class of preservice elementary school teachers in training to become mathematics teachers was involved in this study. Case study research design has theoretical significance in that they are appropriate to for to gain an in-depth understanding of a given phenomenon, establish the need for future research, develop new theories, extend existing theory, etc.

\section{Participants}

The research design that I propose for this study is that of a nested case study. This study is a case of preservice elementary school undergraduate students and the instructor of principles of mathematics course for preservice elementary school teachers at a university in Texas. Nested within the case study of the preservice teachers were four groups of students (two to three students per group) who were selected using purposeful sampling based on their different perspectives/strategies on the problem. Creswell, (2018) states that "often we have found selecting cases that show different perspectives on the problem, process, or event preferable" (p. 100). The first and fourth group had three students each while the second and third group had two students each. The principles of mathematics course are required for students seeking elementary education certification. To be enrolled in the course, students must meet the prerequisite of having earned at least a $\mathrm{C}$ in college algebra. The students in this study varied from a grade of $A$ to $C$ in college algebra. Other than the grade score they had in college algebra, they had very much the same level of mathematical exposure. Studies indicate that the educational system in America under-prepares students in mathematics for college (Allen, 2013). Although efforts are being made such as college readiness initiatives, most high school graduates still struggle with college algebra and the participants in this study are not an exception. During the time the researcher has taught the course, he has found that students bring to the learning context a traditional pre-algebra perspective with more focus on the mechanics of mathematics and less emphasis on the conceptual aspect of mathematics. Similar findings were also noted by Kilpatrick, Swafford, and Findell (2001). The participants of this study seem to be a product of that kind of training since they are always asking for the formula instead of coming up with one. All names used in this paper are pseudonyms.

\section{Procedures}

Before beginning this study, the instructor and I met several times to plan the lessons with an emphasis on the content of the lesson rather than its presentation. At the beginning of the lesson, the instructor presented a buildinga-house problem to the class by using an interactive smart board with dynamic manipulatives, and the students followed along, using pattern blocks to mimic what the instructor was doing. Then, the instructor gave the students another problem to investigate and solve using any method at their disposal. The building-a-house problem the instructor used was formulated to help students develop relationships between inputs and outputs that could lead to generalizations. The class met twice a week for about two weeks on this topic. Students were encouraged to work cooperatively and to jot down their ideas and findings. In helping students think algebraically, the instructor discussed the processes students were using to arrive at their generalizations. It was hoped that by sharing strategies, the preservice teachers would become aware that there is often more than one strategy to solve a problem.

During the lesson, the instructor first asked the students to write down their generalizations and solutions to the problem. As the students worked, the instructor moved around the room, checking their work and asking questions. Then, the instructor collected their work to investigate their strategies deeply and uncover misconceptions.

The instructor returned the students' work and asked them to share their solutions. He walked around the classroom to listen to the conversations. Data collected involved observations of students' discourse, interviews as they solved the problem in their groups, and students' written work. Classroom sessions and interviews were videotaped, and the detailed field notes of the discourse were recorded for analysis. Professional standards for teaching mathematics (1991) defines discourse as:

the ways of representing, thinking, talking, agreeing and disagreeing - is central to what students learn about mathematics as a domain of human inquiry with characteristic ways of 
knowing. Discourse is both the way ideas are exchanged and what the ideas entail: Who talks? About what? In what ways? What do people write, what do they record and why? What questions are important? How do ideas change? Whose ideas and ways of thinking are valued? Who determines when to end a discussion?

\section{DATA COLLECTION AND ANALYSIS}

The students in this study solved ten problems, two of which are the focus of this paper because they presented the greatest challenge to these students. Students provided different strategies to solve each and provided great situations for both students and teachers to learn. I organized and analyzed data, merging students' interviews and work with my observations.

All sessions were videotaped, and interviews were conducted with some students to examine their thinking process at a deeper level. The teaching experiment occurred throughout two weeks. To gain a deeper understanding of how preservice teachers were thinking about these algebra problems, I interviewed with one student after each class to discuss what had occurred during the session. The student was chosen because he acted like a leader of the group and was willing to participate and tended to ask questions in class on a regular basis that needed to be investigated to understand the thinking process. The goal was to understand what the student might have observed, what generalizations the student had formed, mathematical obstacles the student had experienced, and what concepts the student had been able to relate to patterns and generalization. Additionally, I interviewed other students about episodes that arose in class as well as about the teaching experiments in general and focused on student reasoning during these conversations.

I used audiotapes, transcribed and coded the interviews and collected students' work that contained their diagrams and writing. I organized data collected using Nvivo software as a tool for transcribing the video of students' classroom discourse, interviews, and student work. Data were coded to organize and make sense of the interesting patterns that emerged by coding and organizing themes that represent the data collected.

The students' reasoning strategies were also coded, such as functional when a student described a relationship between dependent and independent variables, or recursive if the student used a prior term to determine the next term in the pattern. Other codes used were verbal, graphical, tabular, and symbolic representation. I analyzed data by looking at parts of the data and how those parts are related to the whole investigation.

\section{RESULTS}

The data collection took place in the fall semester of 2011. The course used a problem-solving approach to mathematics for elementary school teachers, with a textbook by Billstein, Libeskind, and Lott (2007). The following sections describe the generalization strategies and justifications that were developed during specific episodes in class discussions. Some cases are reflective of small-group discussion, and others are based on whole-class discussion. The following problems are considered in the order in which they were presented to examine how students' strategies and justifications evolved in the course of the study.

\section{Building-A-House Problem}

The students were presented with the Building-A-House problem as shown in Figure 2. The problem was presented in stages, starting from a stage 1 house, followed by stage 2, stage 3 and so forth. Through the use of the interactive smart board's dynamic manipulatives, the instructor demonstrated the first patterns in the sequence. The instructor asked the student to work in small groups of three and asked them to construct a stage 1 house using the pattern blocks at their tables. Based on stage 1 and 2, the students were asked to predict a Stage 3 house of which they were able to notice the pattern at each stage as one student noted: "To gets the next stage, you add a column of one triangle and two squares stacked up", and then proceeded to draw stage 4 and 5 as shown in Figure 3. Most students in the room were able to draw any stage of the house when requested by the instructor using his potable interactive smart board's dynamic manipulatives connected to an overhead projector for the class to see. Although it seemed to be an easy task for the most student to construct; it was a challenge to some to draw the stage unless they had the previous one insight to add one more column to get the stage. Making the connection between the stage number and then generalize the number of column of two squares and one triangle stacked up that exist was not conceived to some students. 


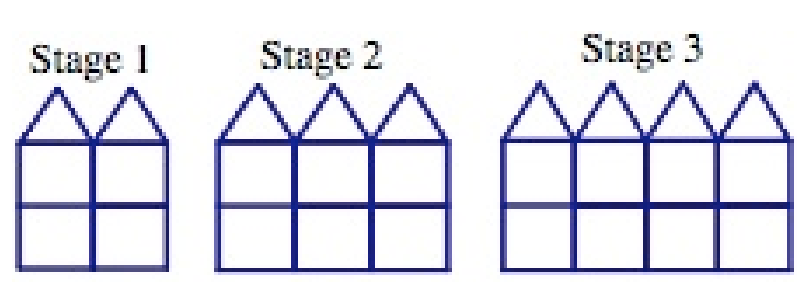

Figure 2. Stage $1-3$ houses
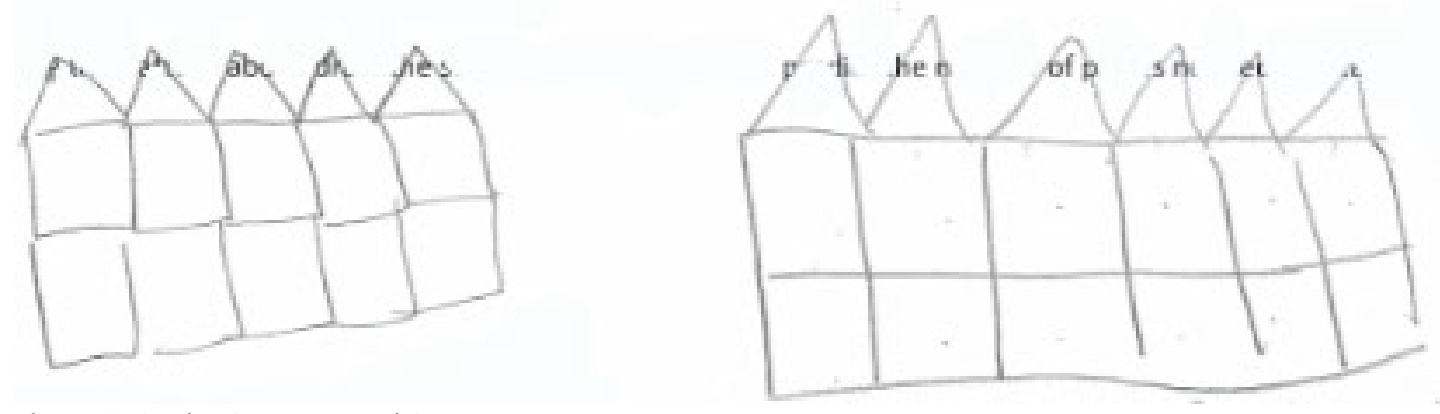

Figure 3. Student's stage 5 and 6

Based on the stages of the houses constructed, the students were asked to organize the data in some way, comparing each stage, describing the pattern, and using what they had observed to find stages 25,100 and (n). Making the connection between the stage and the associated squares and triangles represented, was a challenge. One of the challenges of some students was not how to get the next stage but how to tell the number of squares and triangles that exists at a given stage. The student struggled how to organize data to make sense it as noted:

Student: "Can we make a chart?"

Instructor: "You can make a chart if that is what you think is best. How can we organize it? When you have decided how - then get it organized."

The student had no idea on how to organize the data since there seems to be multiple information that needed to be organized to make sense of it.

Student: Do I consider triangles and squares? Do I consider triangles and squares from one stage to another? And where do I use the total number of pieces in the whole process?"

The instructor encouraged the students to think of the best way to organize the information, the inputs, to see the relationship that exists.

Instructor: "I see a lot of graphs, I see graphing on a coordinate plane. Is this one way of helping me see a pattern?"

Whereas the majority of students organized in a way that helped them make some comparisons or predictions, some still struggle. For instance, some students used the Cartesian plane to plot the number of squares (y) versus the number of triangles $(x)$ or vice versa. Other students had two graphs: the stage number $(x)$ versus the number of squares and the stage number $(\mathrm{x})$ versus the number of triangles $(\mathrm{y})$. In another case, a student used the stage number $(x)$ versus the total number of pattern pieces. Some of these representations were problematic and could not lead to the generalization that students were searching for. For example, the way data was represented in a tabular form determined how the student arrived at a generalization.

The case that seemed to represent data accurately was by Joe whose work is presented in Figure 4. 


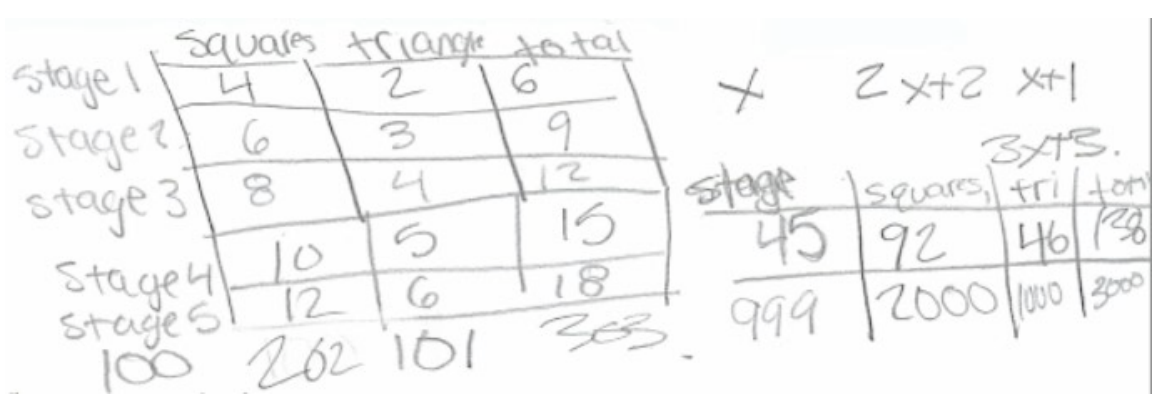

Figure 4. Data organized to access the relationship that existed

The instructor interviewed the student Joe to learn more about his reasoning.

Instructor: “Joe, please build for me stage 7 and tell me how you will go about it."

Joe: "I know how many squares and triangles because it is easy to see the change that happens when they are lined up like that. It is very easy to see how the change happens."

Instructor: "If I want to predict stage $7,8,9, \ldots$ the number of triangles will be?

Joe: “ $8,9,10, \ldots .$, etc."

Instructor: “And total, how many for stage one, two, three...?”

Joe: “6, 9, 12, 15, 18 etc.”

Instructor: "What do you notice?"

Joe: "If I have a current one, I can get the next one."

Instructor: "What if I say to you that I want to know stage 100?"

Joe: "I will have to find the total of the stage from one, two, through one hundred, etc."

Instructor: "Do you want to do that all the way to $100 ?$ ?

Joe: “No."

Instructor: "What about squares?"

Joe: "If my stage number is 1 , I have 4 . If my stage number is 2 , I have 6 . If my stage number is 3 , I have 8 . If my stage number is 4 , I have $10 . "$

Instructor: "How did you arrive at that?"

Joe: "Note that the numbers of squares in each successive term are $6,8,10, \ldots$ adding 2 to get the next number."

The description of Joe's recursive strategy was linked to the relationship between the initial numbers of squares. Joe adds 2 to find the next number of squares. On the other hand, Joe adds 1 to the initial number of the triangles to find the next number of triangles. It was clear that Joe notices that to find the number of triangles, you simply add 1 to the stage number. The relationship between the stage and the number of squares and the total was not as clear to him.

The instructor then displayed the table (Figure 5) on the board for students to explore, with the aim of predicting the total number of pieces used in the stage 100 house. 


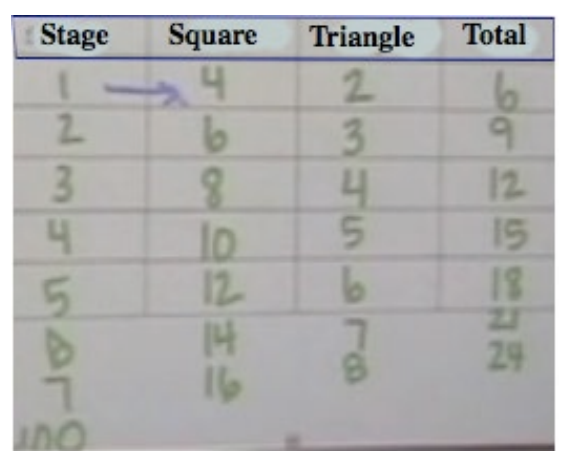

Figure 5. Stage, squares, triangles and total

The students were left to discuss in groups to find the number of squares and triangles required for the stage 100 house. Some concentrated on one column independently, finding a relationship within it in by finding a recursive relationship. Others focused on the relationship between dependent variables, the number of squares and triangles, without bringing into play the independent variable, the stage number. One student, Oira, had trouble figuring out the relationship between the stage number and other variables. He was comfortable with figuring out the number of triangles in the stage 100 house, but finding the number of squares was rather problematic for him as shown in the following excerpt:

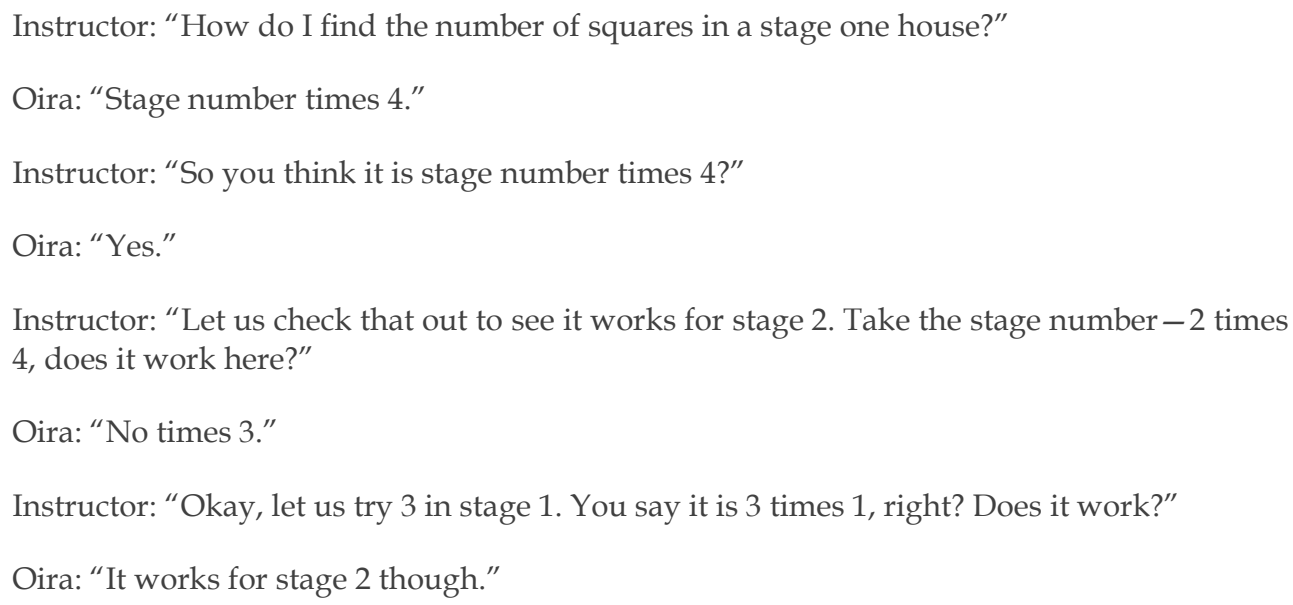

The description of Oira's reasoning was that he looked at one number at a time to find the required stage; however, he was not looking for a rule of the pattern that could be consistent for all of the stages. After this discussion, Oira thought about it and called for the instructor's attention as shown in the following excerpts.

Instructor: "Okay, Oira."

Oira: "I have noted the following: $1+3=4,2+4=6,3+5=8,4+6=10$, etc."

Instructor: "Oira, can you explain what is happening here?"

Oira: "I'm not sure, but just something I came up with."

Instructor: "Okay, that works."

Oira still had trouble relating the stage number and the number of squares. Another student in Oira's group suggested multiplying the stage number by 2 and adding 2 to that product to find the number of squares.

After determining the relationship between the stage number and the number of triangles, the students were challenged to generalize how to find the stage 100 house. In this case, Tongi had the following to note:

Tongi: "I found that the total is always a multiple of three of the number of triangles."

Instructor: "So you are looking at the total?" 
Student: "Yes, I found that 3 times the number of triangles you get the total."

Instructor: "Three times the number of triangles you get the total, yes you are right."

Tongi: "So getting to 100 I got 303, and the triangles are 101; therefore, there are 202 squares."

Instructor: "So you worked backward with this pattern. It gets me there, but it does not help me move from the stage to the total."

Oira arrives at the right answer for finding the stage 100 house by first looking at the number of triangles in the column that was relational, but he was not using the input to get the output since it was a relationship only between outputs. Alternatively, some students looked at finding the stage 100 house by first finding a general way of determining the number of squares and triangles and then summed them up. In this case, if $n$ is the stage number, then the number of squares will be $2 n+2$, and the number of triangles will be $n+1$. Therefore, the total number will be $(2 n+2)+(n+1)=3 n+3$.

\section{Triangular Pattern Problem}

After some lessons, students were presented with a problem similar in some ways to the Building-A-House problem. The problem started:

If this pattern continues, how many dots are in the 50th figure?

$\underline{1 s t}$
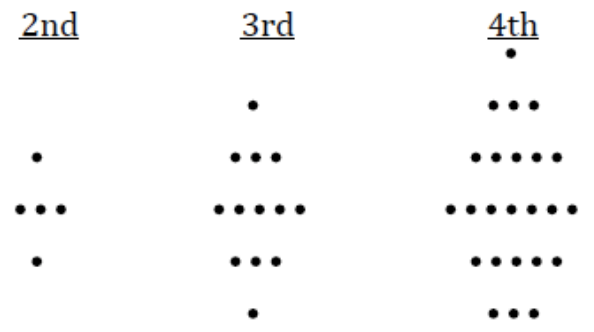

Figure 6. The dot pattern problem

Four episodes are discussed as to how students generalized the pattern. In this problem, students were asked to work in small groups of at most 4 per group. For several groups selected, the results are reported in the following episodes:

\section{First episode}

The first group of three students looked at the pattern and saw a series of triangles. The first strategy these students applied was listing the number of dots for each stage: 1, 5, 13, 25, etc. The students tried to see if there was any relationship between the number of dots and the pattern number but did not make much progress. They tried another strategy in which they drew a line that separated series of triangles as shown below (Figure 7).

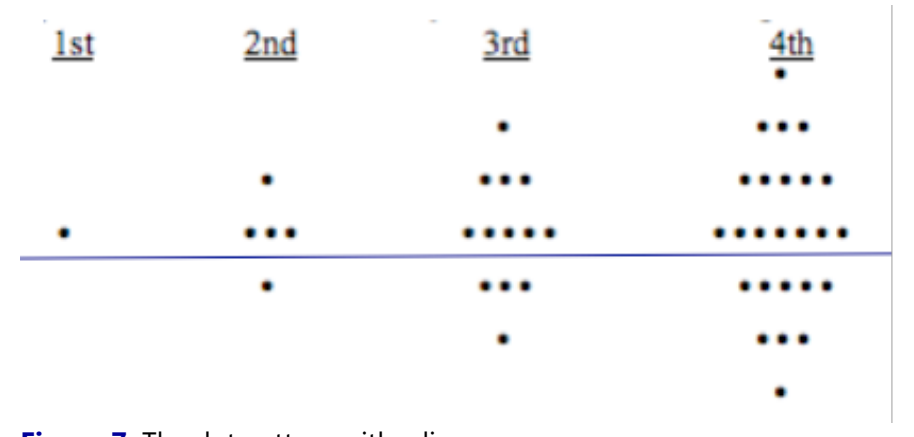

Figure 7. The dot pattern with a line

The students thought they could utilize what they learned about triangular numbers, but that did not work because the triangle series did not form a triangular number sequence. The students then decided to examine the nature of the sequence and the sequence below it. They noted that the number of dots above the line follows this pattern: 1, 4, 9, 16, etc. and the number of dots below the line followed this pattern: $0,1,4$, 9, etc. 
Instructor: "What do you see from the numbers generated?"

Sero: "For dots above the line, I notice that $4-1=3,9-4=5$, and $16-9=7$. We can use these numbers to generate the next number. For example, to get 4 , simply add $1+3=4,4+5=9$ etc."

Instructor: "Now, how are you going to find the 50th number?"

Sero: "I will keep on adding in that way until I find the 50th figure."

Instructor: "What will you do with the dots below the line?"

Sero: "I will do the same as the one above and finally add them up."

Sero's strategy was limited in that he was not able to use the process of generating the next number based on the stage of that number. The instructor then asked Sero's group to consider the stage to find the number of dots.

They decided to represent the data as follows:

Table 1. Stage number numbers of dots above and below the centerline

\begin{tabular}{ccc}
\hline Stage & Dots above the line & Dots below the line \\
\hline 1 & 1 & 0 \\
\hline 2 & 4 & 1 \\
\hline 3 & 9 & 4 \\
\hline 4 & 16 & 9 \\
\hline
\end{tabular}

-

One student in this group noted that it was easy to see what was going on above the line. He noted that a sequence is a square number represented as $1^{2}, 2^{2}, 3^{2}, 4^{2}, \ldots \mathrm{n}^{2}$, but the sequence below the line was somewhat more difficult for them to recognize. The number of dots below the line followed this pattern: $0,1,4,9$, etc. One of the students in the group eventually realized that the pattern $0,1,4,9$, etc. could be represented as $0^{2}, 1^{2}, 2^{2}, 3^{2}, \ldots(n$ $1)^{2}$. At this point, only two in the group understood what was going on - that the table representation had three columns. They were confused about the relationship between the columns. As one student put it, "I'm totally confused, are we moving from the pattern number to the dots above or dots below? It makes my head spin - I like to look at things on a one-to-one basis but not a one-to-many." The students discussed among themselves what to do with the columns and convinced each other to first look at the relationship between the pattern number to dots above the line and the pattern number to dots below the line. To arrive at the total, they simply had to find the sum of the number of dots above and below the line: $n^{2}+(n-1)^{2}$. Therefore, for $n=50$, the number of dots will be (50) $2+\left((50-1)^{2}=(50)^{2}+(49)^{2}=4901\right.$.

\section{Second episode}

In this episode, a group of two students scribbled the result as shown in Figure 8.

When asked to explain what they were doing, one of the students had the following explanation:

We solved for the 49th term to figure out how many dots would be in the center row of the 49 th term. Since the center row sequence is $1,3,5,7$, we noticed that it follows an arithmetic sequence with the first term (a1) being 1 , common difference (d) being 2 . We used the equation an $=\mathrm{a} 1+(\mathrm{n}-1) \mathrm{d}$. Therefore, because the common difference between each center row is 2 , then a $49=1+(49-1) 2=97$. Since in the 50th array there would be 2 rows of 97 as well as everything else, so by letting $S=1+3+5 \ldots+97$. Then,

$$
\begin{aligned}
& S=1+3+5 \ldots+93+95+97 \\
& S=97+95+93 \ldots+5+3+1 \\
& 2 S=98+98+98 \ldots+98+98+98 \\
& 2 S=98 \times 49=4802
\end{aligned}
$$


You don't need to divide by 2 because there are two sets in the 50th array. Since 97 was the center row in the 49 th figure, 99 will be the center in the 50th. So

$4802+99=4901$

You only need one set of 99 because the center row of all the arrays is solitary.

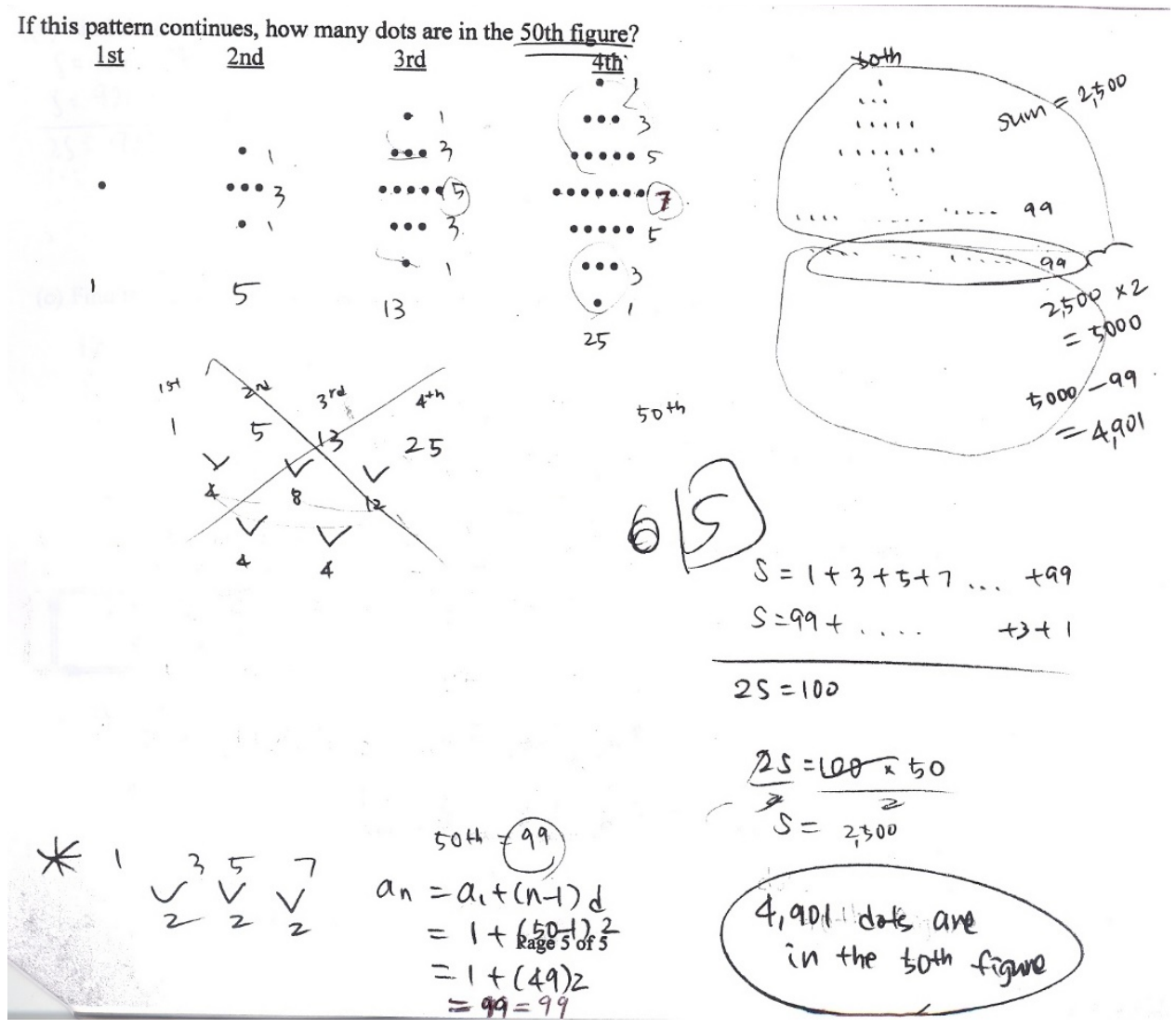

Figure 8. Student's work strategy

As the students discussed their approach, some students had trouble with fundamental concepts in algebraic thinking - the concepts of the first term, last term, the $n$th term, etc. This lack of understanding became obvious as the group discussed the formula $a_{n}=a_{1}+(n-1) d$ regarding making a distinction between $\mathrm{a}_{\mathrm{n}}, \mathrm{a}_{1}$, and $\mathrm{n}$.

\section{Third episode}

In this activity, the group of two students looked at the pattern and noted what they described as a multiple of 4 to get the next number as follows.

$$
\begin{array}{|l|l|l|l|l|}
+4 & +8 & +12 & +15 \\
1, \quad 5, & 13, & 25 &
\end{array}
$$

When they explained the pattern, they were jubilant that their observation could lead them to the result, and surely it did. Two examples that were similar were noticed within the same group. The following are the two results that were similar, but with slightly different representation.

In this task, the students tried to use a diagram (finite differences) to represent the situation and noted that they could model the scenario to be in the form of a table and work through it all the way to the 50th figure (Figure 9). The students constructed a five by ten table as shown and listed the sequence by adding a multiple of four to get the next term all the way to fifty. While the students found the right answer, there was an algebraic misconception in the whole process. When asked to find the $100,000^{\text {th }}$ term or nth term, the students were unable to do so, since they said that 100,000 seemed to be too far off. They had no idea how to find the nth term. 


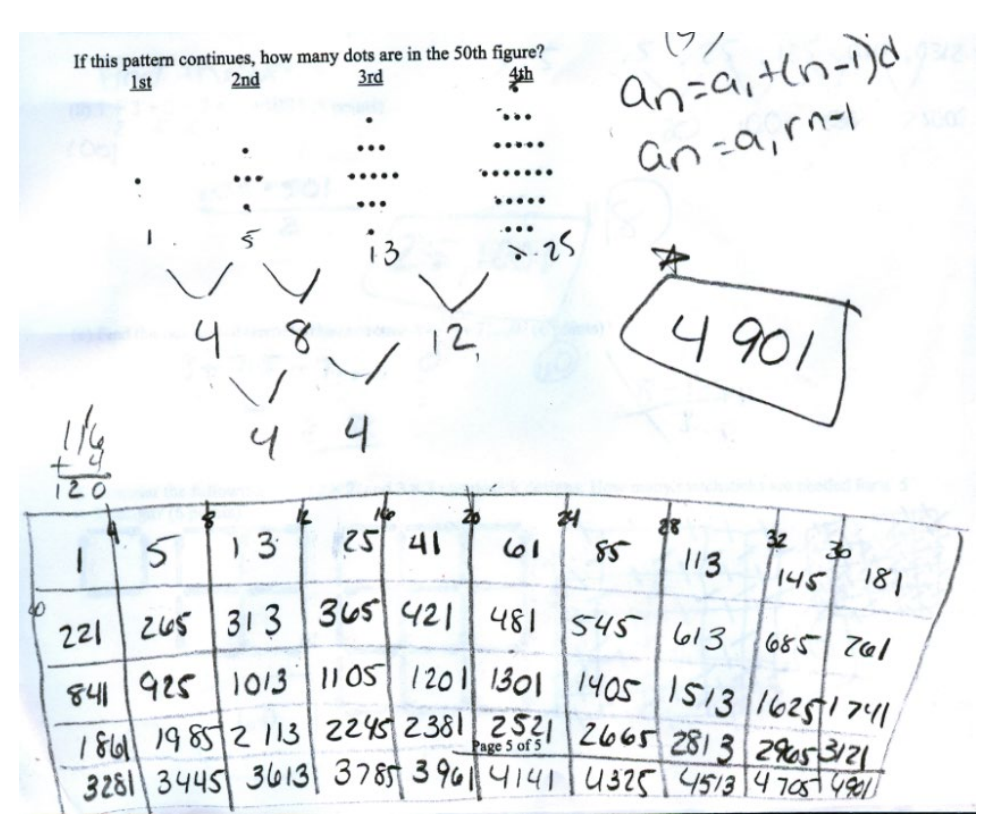

Figure 9. Tabular and finite difference

In this case, the student simply made a table as shown and made the summation of the multiples of 4 that is being added: $1+4+8+12+\ldots+196$.

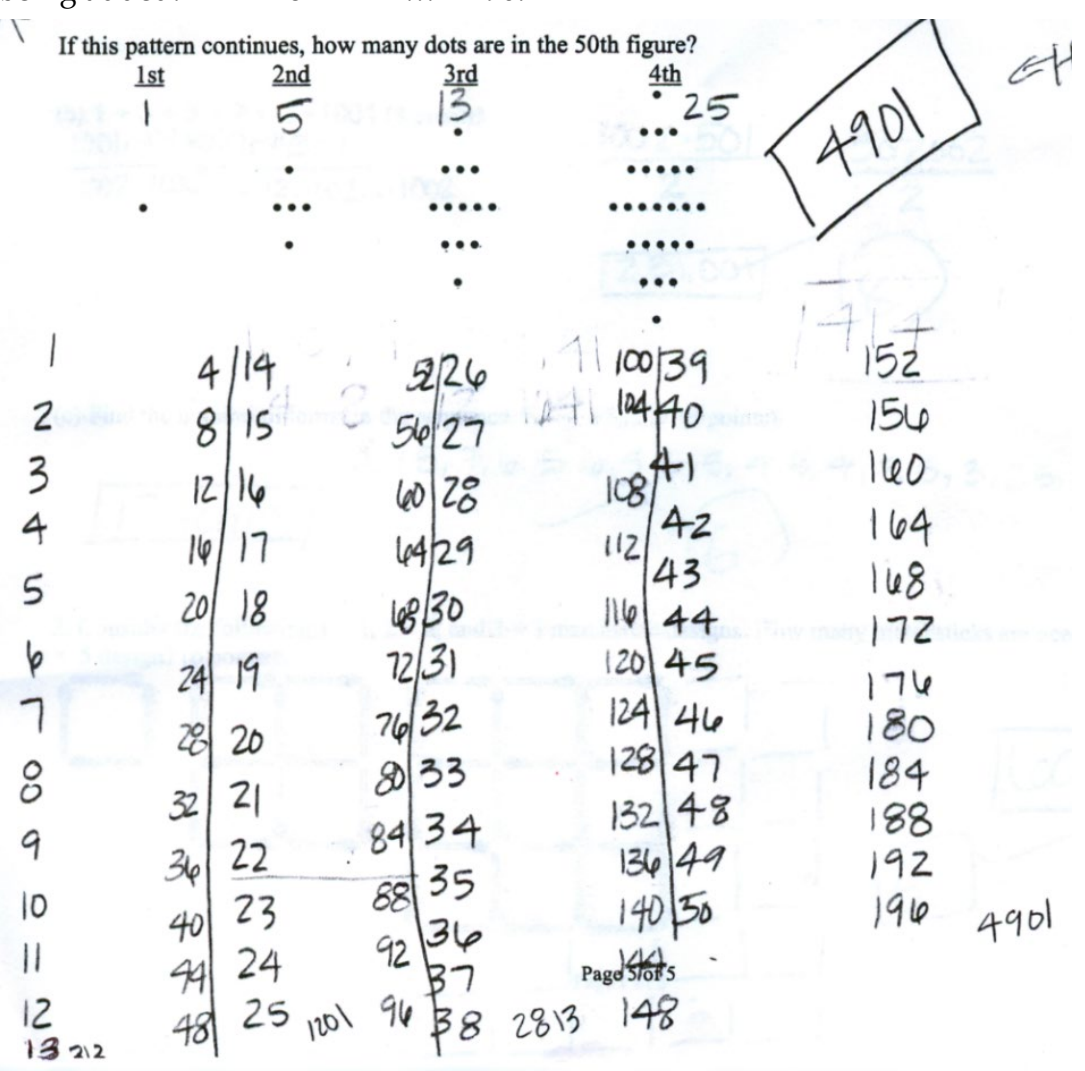

Figure 10. Tabular representation of students' work

The students entered the sum of all the numbers in the calculator to find the total sum as shown in the student work. The instructor then asked them if there might be a shorter way to find the sum, and this question generated discussion. One student noted that the common difference is 4 when the first term is excluded. With that idea, the students decided to use the Gaussian method as shown in the textbook (Billstein, et al., 2007, p. 4) to solve the problem. 


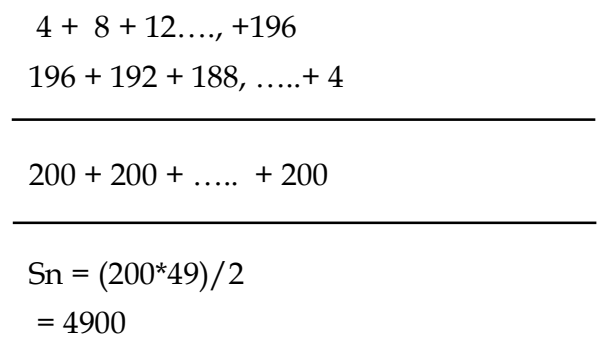

But since 1 is in the sequence and was left out, then the total number of dots was to be $(200 * 49) / 2+1=4901$.

When asked to use that approach to finding the $100,000^{\text {th }}$ term and the nth term, the students were unable to do so but noted that they had solved the problem.

\section{Fourth episode}

There were three students in this group who approached the problem quite differently in many ways but with some similarities to the strategy used in the third episode. They listed the term number and the corresponding number of dots. Based on what they learned in college algebra, the student noted that the finite difference (Figure 11) of the number of dots has two sets of differences. Hence, they noted that it was quadratic.

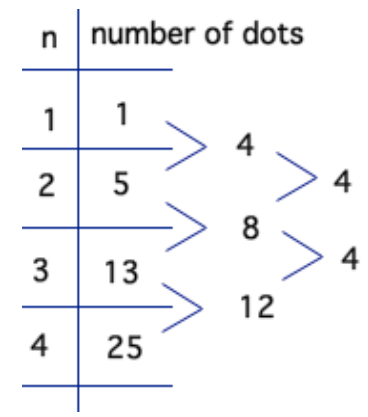

Figure 11. Finite difference

This group of students worked collaboratively and tried different scenarios to come up with a quadratic equation. This was not easy for the group, but one member had the necessary background knowledge to tackle this problem. Since the concept of finite difference was foreign to them, some students in the group were lost in the process. This was evident when the group presented their results as shown below.

Table 2. Stage and number of dots

\begin{tabular}{cc}
\hline Stage & Number of dots \\
\hline 1 & $1=1^{2}$ \\
\hline 2 & $5=2^{2}+1^{2}$ \\
\hline 3 & $13=3^{2}+2^{2}$ \\
\hline 4 & $25=4^{2}+3^{2}$ \\
\hline$\cdot$ & $\cdot$ \\
\hline & $\cdot$ \\
\hline$n$ & $\cdot$ \\
\hline 50 & $n^{2}+(n-1)^{2}$ \\
\hline
\end{tabular}

The concept of having the equation presented as $n^{2}+(n-1)^{2}$ from the information given was challenging for some to understand.

\section{DISCUSSION}

The study provides an opportunity to examine deeply the students' thinking on general rules that they may know and how they may or may not utilize those rules in their reasoning. In this study, the preservice undergraduate students demonstrated that being involved in patterning activities can give students the opportunity to explore some of the challenges the topic of generalization poses and how they can begin to use an 
algebraic framework to generalize similar cases. Tasks similar nature of the triangular pattern problem should be used carefully so as help students conceptualize the rules and operations used to be able to generalize more to "seeing a generality through a particular and seeing the particular in general" (Mason, 1996 p. 65). A similar finding has been arrived at by Lannin (2005) which indicates that "Students' shallow understanding of mathematical operations inhibits the development of algebraic generalization" (P 253).

In this study, the problems presented to the students posed challenges to most of them when they were told to use algebra in their generalization process. In another study, Lee and Wheeler (1987) came to a similar conclusion, stating, "Formulating the algebraic generalization was not a major problem for the [few] students who chose to do so; using it and appreciating it as a general statement was where these students failed" (p. 149). This was the case, even when students had been exposed to pattern activity and went through verbal and symbolic representations since they failed "to see the power of algebra as a tool for representing the general structure of the situation. Without some skill with symbolic manipulations, however, students are unlikely to use algebra to justify generalization" (Kilpatrick et al., 2001, p. 278). In that regard, findings suggest that the challenge to the students was in part the way they chose to represent the numerical pattern and their inability to "identify the strength and the limitations of different forms of representation" (NCTM, 2000 p. 225).

Most students were able to describe verbally, correctly or incorrectly, the situation in some way. The trouble for these students was that they could not identify an algebraic relationship that they could represent with symbolic notation. For instance, in the triangle pattern problems, different representations were presented. In one instance, the students in one group represented their situation by using a table in which they listed the pattern number, the number of dots above the line and the number of dots below the line. The idea of having two dependent variables in the table was problematic to some students. The problem seems to be evident in the two tasks presented even when a student only showed one dependent and one independent variable. Similar findings have been reported by Swafford and Langrall (2000) who note that:

\begin{abstract}
... although making or seeing a table seemed to support some students in their attempts to represent a situation symbolically, for other students a table seemed to hinder their abilities to recognize and describe the relationship between the independent and dependent variables' implicit in the situation. (p. 105)
\end{abstract}

In the two problems presented, it was evident that students used tables to represent the situation and were able to recognize patterns between pairs of independent and dependent variables but were not able to generalize the relationships between the independent and dependent variables.

Another strategy witnessed in the Building-A-House problem was that students used the guess-and-check strategy by using one input value and its output value to generalize the relationship. Students should have realized that a guess-and-check strategy in this instance was not appropriate because it did not lead to a generalization or rule for the nth term. If guess-and-check is used, students need to check all dependent variables and their respective independent variables to justify the relationship (Lee, 1996).

Similarly, in the Building-A-House problem, the students focused on the values in the columns of the table and came up with a recursive rule to find the next term. The next term was not hard to see, but it was difficult "to symbolize algebraically" (Kilpatrick et al., 2001, p. 279) because it did not reflect the idea of a functional relationship even though students could, in some cases, arrive at the answer. For example, in the third and fourth episodes of the triangular pattern problem, students came up with unconventional ways of representing their verbal interpretations by using tables. In both of these instances, the students had a table as a symbolic representation of the situation, which enabled them to get an answer, but did not enable them to represent it symbolically. That is to say; the table emphasized the values that could be used to get an answer rather than focusing on an algebraic relationship to get an answer. Their methods proved to be lacking the notion of an algebraic relationship when students were asked to generalize.

In a study by Warren, (2006) notes that "correct verbal descriptions are more likely to lead to correct algebraic rules and students who could find the correct functional relationship could usually articulate this relationship verbally (p. 378). For this study, students translated their verbal descriptions into symbolic representations more often in the fourth episodes of the triangular pattern problem. They also used multiple representations. In this instance, the students used the diagram showing the finite difference method to assess how the sequence changed. Then, based on that, they used the results in the table representation of the situation to see the algebraic relationship between the independent and dependent variables. This did not, however, come easily - some students had a hard time linking the diagram, a table, and the relationship between the contexts of the problem presented (Dreyfus, 1991). Therefore "generalization via pattern problems can be an invaluable means for developing and revealing the intuitive algebraic skills (p. 128). 


\section{Conclusion and Future Directions}

The need to introduce students to pattern activities early in their lives is crucial. For this to be possible, preservice teachers need to be prepared to perform that task effectively. Preservice teachers need to acquire the pedagogical content knowledge in algebra that will play a critical role in their teaching algebraic concepts and skills. To provide meaningful contexts to help preservice teachers improve their pedagogical content knowledge, mathematics educators might want to investigate the various strategies their students use when asked to use their algebraic skills to explore and solve novel problems.

\section{REFERENCES}

Allen, J. (2013). Updating the ACT College Readiness Benchmarks. ACT Research Report Series 2013 (6). ACT, Inc.

Amit, M., \& Neria, D. (2008). "Rising to the challenge": Using generalization in pattern problems to unearth the algebraic skills of talented pre-algebra students. ZDM, 40(1), 111-129. https:/ / doi.org/10.1007/s11858-0070069-5

Arzarello, F. (1992). Praic pre-algebraic problem solving In J. P. Ponte, J. F. Matos, J. M. Matos \& D. Fernandes (Eds.), Mathematical problem solving and new information technologies (Vol. 89, pp. 155-166). Berlin: SpringerVerlag. https:/ / doi.org/2010.1007/978-3-642-58142-7

Bay-Williams, J. M., Skipper, E. M., \& Eddins, S. K. (2004). Developing a well-articulated algebra curriculum: Examples from the NCTM academy for professional development. In R. N. Rubenstein \& G. W. Bright (Eds.), Perspective on the teaching of mathematics: Sixty-sixth yearbook of the National Council of Teachers of Mathematics yearbook (pp. 15-26). Reston, VA: National Council of Teachers of Mathematics.

Billings, E. (2008). Exploring generalization through growth patterns. In C. E. Greenes \& R. Rubenstein (Eds.) Algebra and algebraic thinking in school mathematics: Seventieth yearbook (pp. 279-293). Reston, VA: National Council of Teachers of Mathematics.

Billstein, R., Libeskind, S., \& Lott, J. W. (2007). Problems solving approach to mathematics for elementary school teachers (9th ed.). Boston: Pearson Eductional, Inc.

Brown, T. (2001). Mathematics education and language: Interpreting hermeneutics and post-structuralism. Dordrecht, The Netherlands: Kluwer Academic. https:/ / doi.org/10.1007/978-94-010-0726-9

Burgis, K., \& Morford, J. (2008). Investigating college algebra with technology. Oakland, CA: Key curriculum press.

Chazan, D. (2008). The shifting landscape of school algebra in the United States. In C. Greenes \& R. N. Rubenstein (Eds.), Algebra and algebraic thinking in school mathematics: Seventieth yearbook (pp. 19-25). Reston, VA: National Council of Teachers of Mathematics.

Cuevas, G. J., \& Yeatts, K. (2001). Navigating through algebra in grades 3-5. Reston, VA: National Council of Teachers of Mathematics.

Dienes, Z. P. (1961). On abstraction and generalization. Harvard Educational Review, 3, 289-301.

Dreyfus, T. (1991). Advanced mathematical thinking process. In D. Tall (Ed.), Advanced mathematical thinking (pp. 25-41). Dordrecht, The Netherland: Kluwer. https:/ / doi.org/10.1017/CBO9781139013499.008

Driscoll, M. J. (1999). Fostering algebraic thinking: A guide for teachers, grades 6-10. Portsmouth, N.H.: Heinemann.

Greenberg, J., \& Walsh, K. (2008). No common denominator: The preparation of elementary teachers in mathematics by America's education schools. Retrieved from http:/ / nctq.org

Healy, L., \& Hoyles, C. (1999). Visual and symbolic reasoning in mathematics: Making connections with computers. Mathematical Thinking and Learning, 1, 59-84. https:/ / doi.org/10.1207/s15327833mt10101_3

Kaput, J. (2000). Transforming algebra from an engine of inequity to an engine of mathematical power by "algebrafying" the K-12 curriculum. Dartmouth, MA: National Center for Improving Student Learning and Achievement in Mathematics and Science.

Kaput, J. J. (2008). What is algebra? What is algebraic reasoning? In J. J. Kaput, D. W. Carraher \& M. L. Blanton (Eds.), Algebra in the early grades (pp. 5-18). New York: Lawrence Erlbaum Associates.

Kieran, C. (1992). The learning and teaching of school algebra. In D. A. Grouws (Ed.), Handbook of research on mathematics teaching and learning (pp. 390 - 419). New York: Macmillan.

Kilpatrick, J., \& Izsak, A. (2008). A history of algebra in the school curriculum. In C. Greenes (Ed.), Algebra and algebraic thinking in school mathematics: 2008 NCTM yearbook (pp. 3-18). Reston, VA: NCTM.

Kilpatrick, J., Swafford, J., \& Findell, B. (2001). Adding it up: Helping children learn mathematics. Washington, DC: National Academy Press. 
Kilpatrick, J., Swafford, J., \& Findell, B. (2001). Adding it up: Helping children learn mathematics. Washington, DC: National Academy Press.

Lannin, J. K. (2005). Generalization and justification: The challenge of introducing algebraic reasoning through patterning activities. Mathematical Thinking and Learning, 7(3), 231-258. https://doi.org/10.1207/s15327833mt10703_3

Lee, L. (1996). An initiation into algebraic culture through generalization activities. In N. Bednarz, C. Kieran \& L. Lee (Eds.), Approaches to Algebra: Perspectives for Research and Teaching (pp. 87-106). Dordrecht: Kluwer Academic Publishers. https:/ / doi.org/10.1007/978-94-009-1732-3_6

Lee, L., \& Wheeler, D. (1987). Algebraic thinking in high school students: Their conceptions of generalization and justification (Research report). Montreal: Concordia University, Mathematics Department.

Malara, N., \& Navarra, G. (2003). April Project: Arithmetic pathways towards favoring pre-algebraic thinking. Bologna: Pitagora Editrice.

Mason, J. (1996). Expressing generality and roots of algebra. In L. Lee (Ed.), Approaches to algebra: Perspectives for research and teaching (pp. 65-86). Dordrecht, The Netherlands: Kluwer Academic. https:/ / doi.org/10.1007/978-94-009-1732-3_5

McCrory, R., Floden, R., Ferrini-Mundy, J., Reckase, M. D., \& Senk, S. L. (2012). Knowledge of algebra for teaching: A framework of knowledge and practice. Journal for Research in Mathematics Education, 43(5), 584-615. https://doi.org/10.5951/jresematheduc.43.5.0584

National Council of Teachers of Mathematics (2000). Principles and standard for school mathematics: Reston, VA: Author.

Patton, M. Q. (2015). Qualitative evaluation and research methods (p. 5321990). Newbury Park, CA: Sage

Radford, L. (2000). Signs and meanings in students' emergent algebraic thinking: A semiotic analysis. Educational Studies in Mathematics, 42, 237-268. https:/ / doi.org/10.1023/ A:1017530828058

Smith, E. (2003). Stasis and change: Integrating pattern, functions, and algebra throughout the K-12 curriculum. In J. Kilpatrick, W. G. Martin \& D. Schifter (Eds.), A research companion to principles and standards for school mathematics (pp. 135-150). Reston, VA: National Council of Teachers of Mathematics. https://doi.org/10.1002/jsc.645

Smith, E. (2008). Representational thinking as a framework. In J. J. Kaput, D. W. Carraher \& M. L. Blanton (Eds.), Algebra in the early grades (pp. 133-160). New York: Lawrence Erlbaum Associates.

Spradley, J. P. (1980). Participant Observation. Chicago: Holt, Rinehart, and Winston.

Stacey, K. (1989). Finding and using patterns in linear generalizing problems. Educational Studies in Mathematics, 20, 147-164. https:/ / doi.org/10.1007/BF00579460

Steffe, L. P., \& Thompson, P. W. (2000). Teaching experiment methodology: Underlying principles and essential elements. In A. E. Kelly \& R. A. Lesh (Eds.), Handbook of research design in mathematics and science education (pp. 267-307). Mahwah, NJ: Erlbaum.

Stephens, A. (2008). What "counts" as algebra in the eyes of preservice elementary teachers? Mathematical Behavior, 27, 33-47. https:// doi.org/10.1016/j.jmathb.2007.12.002

Swafford, J. O., \& Langrall, C. W. (2000). Grade 6 students' preinstructional use of equation to describe and represent problem situations. Journal for Research in Mathematics Education, 31(1), 89-112. https:/ / doi.org/10.2307/749821

von Glasersfeld, E. (1995). Radical constructivism: A way of knowing and learning. London: Falmer Press. https:/ / doi.org/10.4324/9780203454220

Warren, E. (2000). Learning comparative mathematical language in the elementary school: A longitudinal study. Educational Studies in Mathematics, 62(2), 169-189. https:/ / doi.org/10.1007/s10649-006-4627-5

Warren, E. (2006, July). Teacher actions that assist young students write generalizations in words and in symbols. In Proceedings of the 30th Conference of the International Group for the Psychology of Mathematics Education (Vol. 5, pp. 377-384).

Yin, R. K. (2017). Case study research and applications: Design and methods. Sage publications.

Zazkis, R., \& Liljedehl, P. (2002). Generalization of patterns: The tension between algebra thinking and algebraic notation. Educational Studies in Mathematics, 49, 379-402. https:/ / doi.org/10.1023/ A:1020291317178

\section{http://www.ejmste.com}

